\title{
Clinical Reasoning: An unusual cause of adult cryptogenic ischemic stroke
}

Mark L. Leekoff, MD, Julia E. Masur, BS, Allen P. Burke, MD, Jeremy S. Pollock, MD, Matthew N. Peters, MD, Si M. Pham, MD, Timothy R. Miller, MD, and John W. Cole, MD, MS

Neurology ${ }^{\circledR}$ 2018;90:386-391. doi:10.1212/WNL.0000000000004995

\section{Section 1}

A 60-year-old woman, a nonsmoker, with medical history of hypertension and chronic back pain, presented with sudden-onset left-sided weakness and facial droop to an outside hospital with symptoms of approximately 1 hour duration. Her NIH Stroke Scale (NIHSS) score, a validated tool to quantitatively measure stroke severity, ${ }^{1}$ was 17 , significant for a right gaze preference, left-sided hemiparesis, and left-sided neglect. Her initial head CT demonstrated an Alberta Stroke Programme Early CT Score (ASPECTS) of 9. ASPECTS is a 10-point quantitative CT scan topography score used to measure ischemic changes on head CT. ${ }^{2}$ The patient's head CT demonstrated subtle right basal ganglia ischemic involvement and an absence of hemorrhage. IV tissue plasminogen activator (tPA) was administered and CT angiography of the head and neck was performed, demonstrating a right middle cerebral artery (MCA) (M1) occlusion. Our institution was consulted as per protocol for ischemic strokes associated with large artery occlusion and she was transferred for potential intra-arterial (IA) thrombectomy. Upon arrival, the patient was mildly lethargic but attended to the examination; she was able to follow simple commands to open/close her eyes and make a fist. The patient was dysarthric, but with time, answered questions appropriately. She had left-sided facial weakness and right gaze preference but was able to cross midline. She demonstrated left-sided neglect to visual and tactile stimuli and was slow to move her left extremities to repeated command, with decreased left-sided extremity strength rated 4/5. NIHSS upon arrival to our institution was 9.

Given the patient's somewhat improved deficits since symptom onset, now at $\sim 2.5$ hours, and the use of IV tPA, a rapid sequence MRI of the brain was performed to evaluate the burden of completed stroke, to verify no hemorrhagic transformation, and to evaluate clot burden. Brain MRI demonstrated patchy deep right MCA (right MCA) ischemia involving the basal ganglia, but the cortical regions were spared. Notably, brain MRI susceptibility-weighted imaging (SWI) did not demonstrate a typical clot blooming susceptibility artifact, also known as a susceptibility vessel sign (figure 1), calling into question whether the occlusion had resolved as a result of the IV tPA use. MRI SWI is particularly sensitive to compounds that alter the local magnetic field, making it useful in detecting acute thrombus, deoxygenated blood in veins, hemosiderin, calcium, and iron. ${ }^{3}$ As such, blood clots lodged in proximal intracranial vessels can often be visualized. Several studies evaluating SWI in such situations have demonstrated that the susceptibility sign has a sensitivity of low $80 \%$, and an extremely high specificity ( 100\%). ${ }^{4,5}$ Time-of-flight magnetic resonance angiography (MRA) of the head and neck was then performed and demonstrated a persistent right M1 occlusion. There was no evidence of atherosclerosis or dissection in the proximal right-sided arteries, nor was any atherosclerosis seen in the other vessels of the head and neck. The patient was in normal sinus rhythm without ectopy. Duration between last known normal and time to groin puncture was 4 hours and 46 minutes. Duration from arrival to our facility to groin puncture time was 1 hour and 41 minutes. While additional information was obtained from the MRI study, obtaining these studies induced some time delay in the initiation of the thrombectomy procedure.

\author{
Correspondence \\ Dr. Cole \\ jcole@som.umaryland. \\ edu
}


Figure 1 Time-of-flight (TOF) magnetic resonance angiography (MRA) and susceptibility-weighted imaging (SWI) MRI
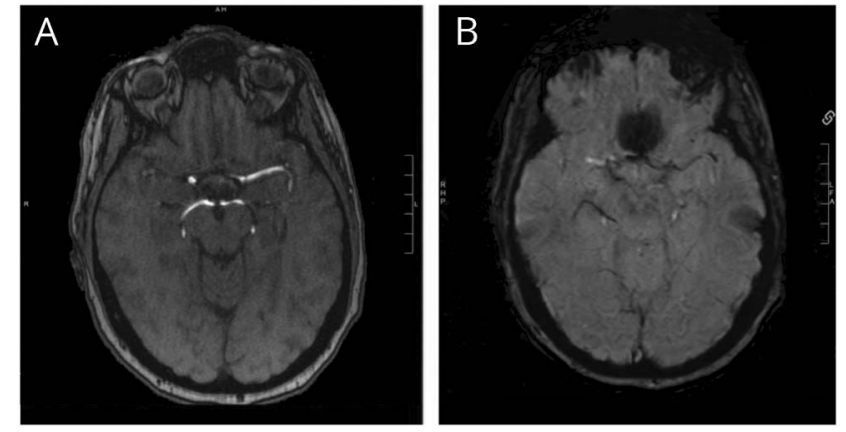

(A) TOF MRA demonstrates occlusion of the right middle cerebral artery (MCA). (B) SWI MRI demonstrates absent "blooming" as might be expected from a clot in right MCA.

\section{Questions for consideration:}

1. Given the timing from symptom onset, the examination with cortical deficits (neglect), and some completed infarct on MRI but with cortical sparing, is this an appropriate patient to consider for thrombectomy?

2. How might one explain what appears to be a clot on MRA, but a lack of blooming artifact on the SWI? 


\section{Section 2}

IA thrombectomy was successfully performed and the extracted clot was sent to pathology for analysis. The patient's post-thrombectomy Thrombolysis in Cerebral Infarction (TICI) perfusion score was rated as grade 3, indicating full reperfusion. The TICI scale is used to describe angiographic intracranial flow. ${ }^{6}$ Also, postprocedure, the patient was started on atorvastatin at a dose of $80 \mathrm{mg}$ daily, which was later decreased to $40 \mathrm{mg}$ daily, given her excellent lipid numbers and lack of atherosclerotic disease. The patient was additionally started on aspirin $81 \mathrm{mg}$ at 24 hours post IV tPA. A transthoracic echocardiogram (TTE) demonstrated a small patent foremen ovale (PFO), but was otherwise unremarkable. Because of the presence of a PFO, although the patient had no history of deep vein thrombosis (DVT), recent extremity injury, or other sequela of DVT, she underwent bilateral lower extremity Doppler to evaluate for DVT as a paradoxical embolus source; these studies were negative. EKG was normal, as were serial cardiac troponins. Continuous cardiac monitoring demonstrated no ectopy and the patient remained in normal sinus rhythm throughout her hospitalization. Her examination markedly improved early into her hospitalization, with resolution of her neglect and gaze preference, and returning to near full strength in her left-sided extremities. All standard stroke laboratory studies including a thyroid panel, toxicology screen, fluorescent treponemal antibody/ rapid plasma reagin, HgbAlC, erythrocyte sedimentation rate, and high-sensitive C-reactive protein were within normal limits.

\section{Questions for consideration:}

1. What other tests should be considered in a patient with cryptogenic stroke?

2. Can you think of any benefit for sending the extracted clot to pathology for analysis? 


\section{Section 3}

As the patient showed marked clinical improvement, she was prepared for discharge. The follow-up plans included outpatient cardiac event monitoring to evaluate for paroxysmal atrial fibrillation, as well as standard vascular risk factor control including a daily aspirin, statin therapy, and her home blood pressure medications. On the day prior to her planned discharge, histologic analysis of the extracted "clot" returned, demonstrating that the clot was actually a fragment of a cardiac papillary fibroelastoma (PFE). Given the absence of evidence of a PFE on the TTE, transesophageal echocardiography (TEE) was performed, clearly demonstrating a $1 \times 1 \mathrm{~cm}$ mobile mass on the aortic valve consistent with a PFE (figure 2, B-D). The attachment site of the visualized echodensity appeared to be on the aortic valve commissures between the right and left coronary cusps. Upon re-review of the TTE, the PFE was potentially visualized (figure $2 \mathrm{~A}$ ).

\section{Questions for consideration:}

1. Should all cryptogenic ischemic stroke patients undergo TEE?

2. Should all cryptogenic ischemic stroke patients undergo outpatient cardiac event monitoring?

Figure 2 Transesophageal echocardiography (TEE)
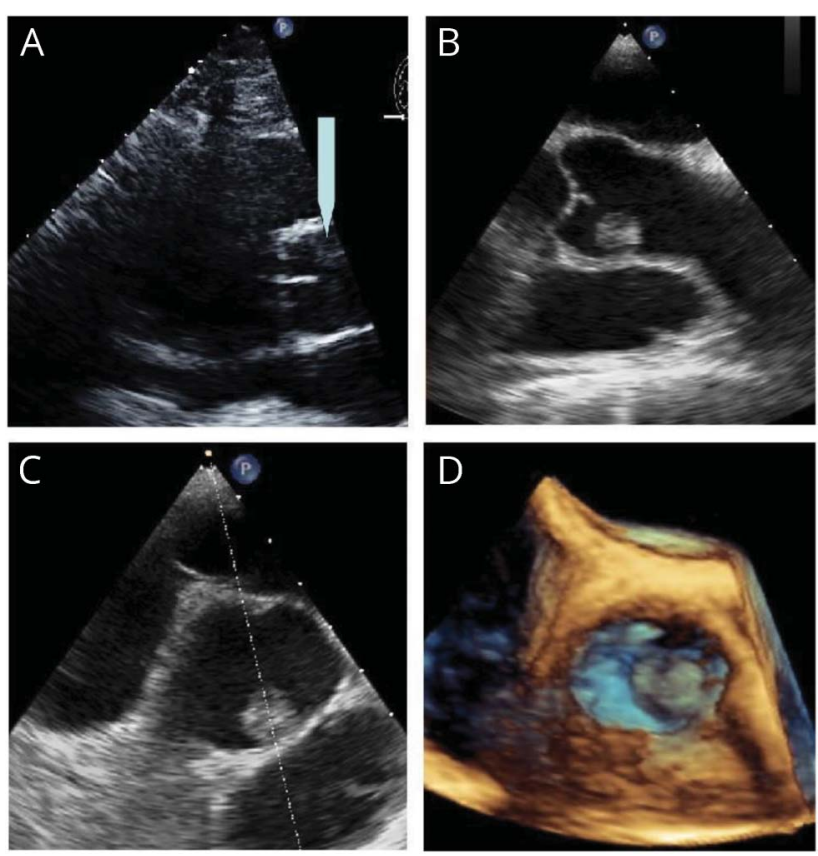

(A) Re-review of transthoracic echocardiogram depicts potential echodensity (arrow) attaching to the aortic valve commissures between the right and left coronary cusps in short axis. (B) TEE depicts $1 \times 1 \mathrm{~cm}$ papillary fibroelastoma attaching to the aortic valve commissures between the right and left coronary cusps in long axis. (C) TEE depicts $1 \times 1 \mathrm{~cm}$ papillary fibroelastoma attaching to the aortic valve commissures between the right and left coronary cusps valve in short axis. (D) 3D echocardiography depicts $1 \times 1 \mathrm{~cm}$ papillary fibroelastoma attaching to the aortic valve commissures between the right and left coronary cusps in short axis.

GO TO SECTION 4 


\section{Section 4}

Because of the embolic potential of the PFE, cardiothoracic surgery was consulted for further management recommendations. Given the small residual stroke burden consistent with the patient's clinical improvement to a near normal examination, the patient was kept in-house for a surgical PFE excision procedure.

\section{Question for consideration:}

1. Regarding the surgical excision of the symptomatic PFE, what factors would you consider regarding the timing of the procedure?

Both stroke burden and brain at risk, as well as PFE size, were considered regarding the timing of the surgical PFE extraction. Cardiac surgery was performed on day 14 status post stroke. The extracted PFE (figure 3) measured $1.0 \times 1.0 \times 1.0$ $\mathrm{cm}$ and was attached to the aortic valve commissures between the right and left coronary cusps. There was no pedunculated stalk. The residual PFE was shaved off the valve leaflets.

\section{Discussion}

PFEs are the second most common cardiac tumor after myxomas. ${ }^{7,8}$ While PFEs are generally benign, they can rarely cause a cryptogenic adult-onset ischemic stroke. In older adults, cardiac emboli are a well-known manifestation of atrial

Figure 3 Surgically resected fibroelastoma specimen, $1.0 \times$ $1.0 \times 1.0 \mathrm{~cm}$

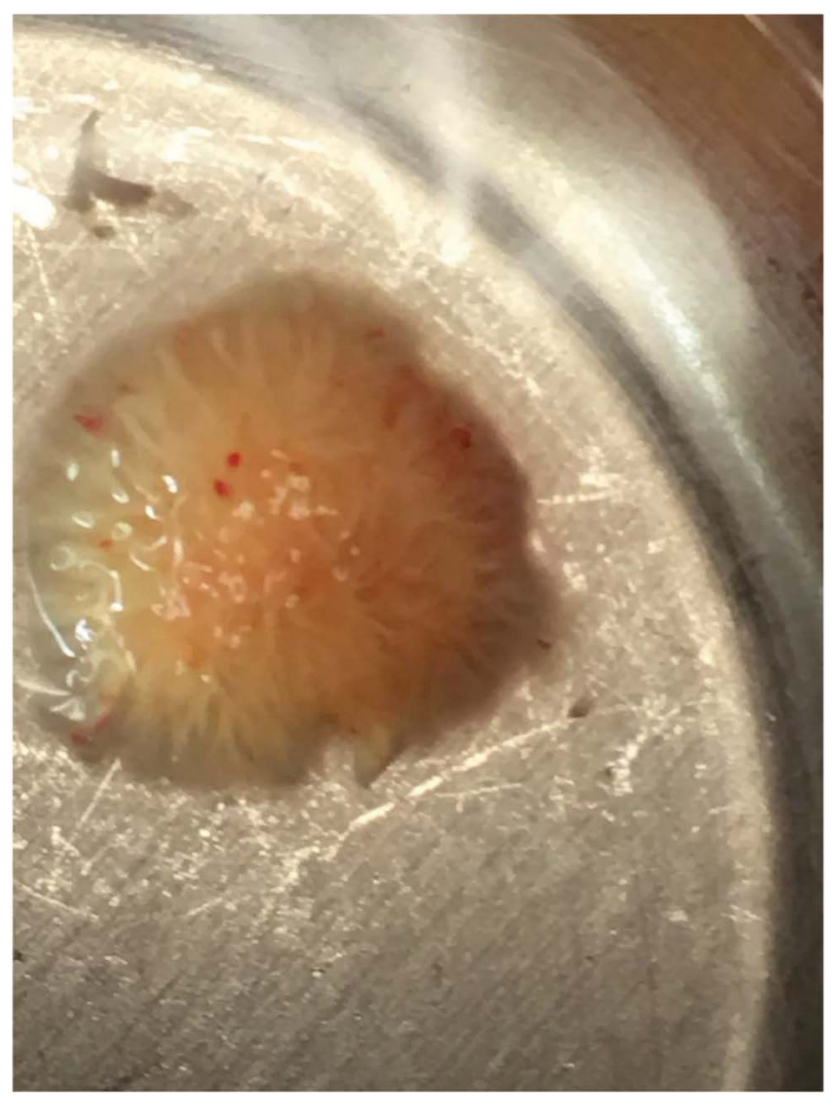

fibrillation; however, in the setting of primary cardiac tumors, including PFEs, small pieces of the tumor can embolize to the brain and cause signs and symptoms consistent with an embolic blood clot. ${ }^{7}$ Our report describes an unusual case of ischemic stroke in an otherwise healthy 60-year-old woman without substantial vascular risk factors, highlighting the key clinical decision points leading to the ultimate diagnosis of right MCA occlusion secondary to embolization from a previously undiagnosed cardiac PFE.

Histologically and consistent with our specimen (figure 4), PFEs appear as papillary fronds of dense connective tissue, elastic tissue, and reticulin, surrounded by loose connective tissue composed of acid mucopolysaccharide, collagen fibrils, elastic fibers, and occasional mononuclear cells. These fronds are covered by hyperplastic endothelial cells. ${ }^{9}$ Although PFEs have been reported as large as $7 \mathrm{~cm}$, most are $<1.5 \mathrm{~cm} .{ }^{8,9}$ Over $80 \%$ of PFEs are valvular, most commonly affecting the aortic and mitral valves, while the most common nonvalvular location is the left ventricle. ${ }^{7}$ There are no clear associated risk factors. ${ }^{10}$

Figure 4 The tumor and the papillary structures
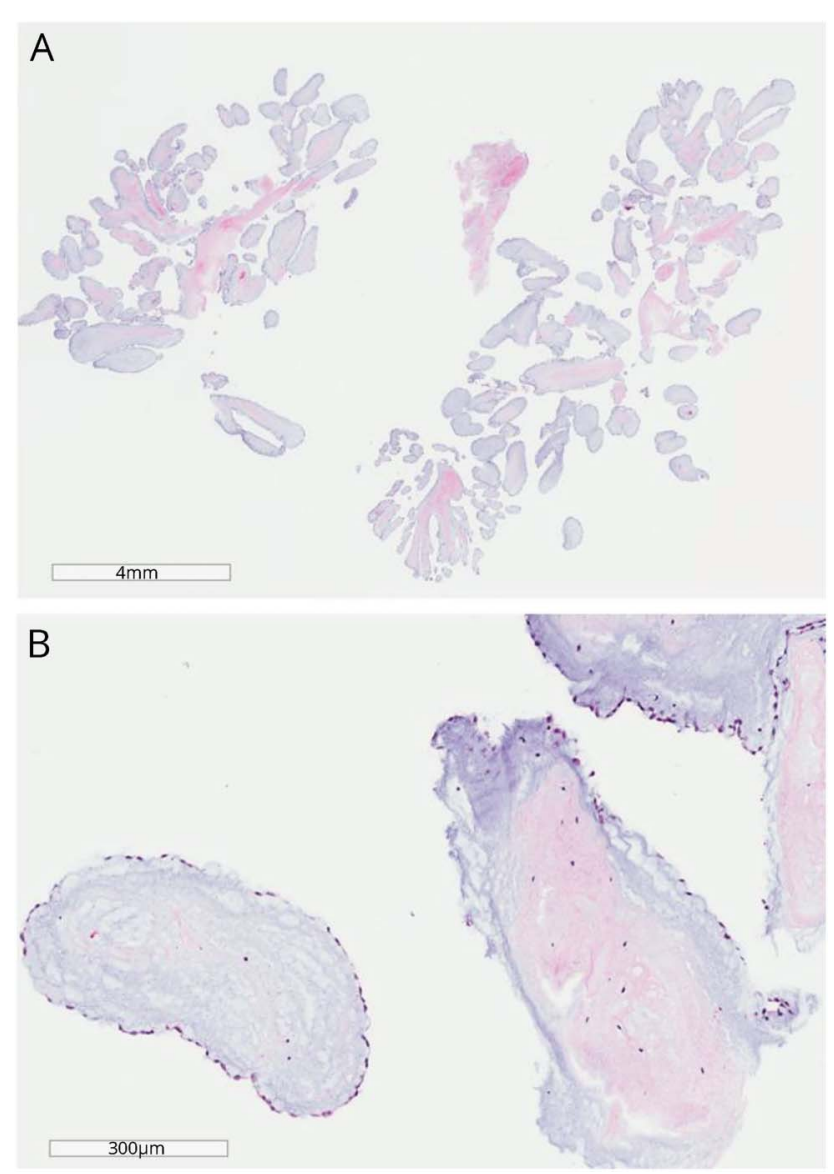

(A) The tumor at low magnification is composed of multiple branching papillae. (B) At high magnification, the papillary structures are avascular and are filled with amorphous myxoid ground substance. There is a single surface lining of endothelial cells. 
PFEs may appear in patients at any age and are typically detected by age 60 , with no clear sex predilection. ${ }^{8,9}$ The majority of these lesions are asymptomatic, although leftsided lesions are more likely to be symptomatic than rightsided lesions. ${ }^{9,10}$ Symptoms associated with right-sided lesions may include right ventricular outflow obstruction, palpitations, weakness, and cyanosis., ${ }^{9,10}$ Left-sided lesions tend to produce symptoms via embolization, either of the tumor itself or of thrombi attached to the tumor surface. ${ }^{9,10}$ Data regarding brain embolization rate are scant but one study done by Anastacio et al. ${ }^{11}$ showed that embolization to the brain was seen in $30 \%$ of the patients $(n=23)$ who underwent surgical resection of PFE.

TEE is the diagnostic study of choice because these lesions can be missed by TTE, as demonstrated in our case. ${ }^{9}$ TEE often reveals a small highly mobile mass with a pedunculated stalk attached to valve or endocardial surface, with a frond-like appearance. ${ }^{12}$

Surgical resection is recommended for patients who have had embolic events/complications, or for highly mobile or large $(>1 \mathrm{~cm})$ masses. ${ }^{8,10}$ Given the typical peduncular appearance of PFEs, the majority of tumors can be removed via stalk excision with valve repair. ${ }^{8,10}$ Minimally invasive procedures via partial sternotomy may be used as an alternative to traditional full median sternotomy. A minority of tumors may require valve replacement. ${ }^{13}$ To date, clinical evidence of PFE recurrence following surgical excision is lacking. ${ }^{11}$ Long-term oral anticoagulation may be recommended for patients who are not candidates for surgical excision, although there are no randomized controlled trials demonstrating the efficacy of long-term anticoagulation for the prevention of embolic events in the setting of PFEs. ${ }^{8,10}$

We describe the clinical presentation of an embolic stroke that occurred as a result of a cardiac papillary fibroelastoma. We highlight the presentation, diagnosis, and treatment of papillary fibroelastoma. There are several teaching points in this case. First, the lack of blooming artifact on the MRI SWI increased our desire to send the clot specimen for pathologic analysis, although PFE was not on our radar. Second, the histologic clot analysis proved useful in the diagnosis. Third, the initial TTE did not demonstrate the PFE that was seen on TEE. Without the histologic results, we may not have performed the TEE and the etiology of stroke would have been missed. In the setting of a cryptogenic stroke, a cardiac event monitor would have been performed, but this would have returned negative for arrhythmia. As such, we suggest performing a TEE in all cryptogenic stroke patients if the TTE is unrevealing. If the TEE is also unrevealing, it is appropriate to proceed with standard outpatient cardiac event monitoring.

\section{Author contributions}

Dr. Leekoff and Julia Masur co-wrote the initial draft of the manuscript and performed critical revision of the manuscript for important intellectual content. Drs. Burke, Pollock, Peters, Pham, and Miller performed critical revision of the manuscript for important intellectual content. Dr. Cole performed critical revision of the manuscript for important intellectual content and led the case write-up and submission. All authors participated in the clinical care of the patient described.

\section{Study funding}

No targeted funding reported.

\section{Disclosure}

The authors report no disclosures relevant to the manuscript. Go to Neurology.org/N for full disclosures.

\section{References}

1. Brott T, Adams HP, Olinger CP, et al. Measurements of acute cerebral infarction: a clinical examination scale. Stroke 1989;20:864-870.

2. Barber PA, Demchuk AM, Zhang J, et al. Validity and reliability of a quantitative computed tomography score in predicting outcome of hyperacute stroke before thrombolytic therapy: ASPECTS Study Group: Alberta Stroke Programme Early CT Score. Lancet 2000;355:1670-1674.

3. Naik D, Viswamitra S, Kumar A, Srinath M. Susceptibility weighted magnetic resonance imaging of brain: a multifaceted powerful sequence that adds to understanding of acute stroke. Ann Indian Acad Neurol 2104;17:58.

4. Rovira A, Orellana P, Alvarez-Sabín J, et al. Hyperacute ischemic stroke: middle cerebral artery susceptibility sign at echo-planar gradient-echo MR imaging. Radiology 2004;232; 466-473.

5. Flacke S, Urbach H, Keller E, et al. Middle cerebral artery (MCA) susceptibility sign at susceptibility-based perfusion MR imaging: clinical importance and comparison with hyperdense MCA sign at CT1. Radiology 2000;215:476-482.

6. Fugate JE, Klunder AM, Kallmes DF. What is meant by "TICI"? AJNR Am J Neuroradiol 2013;34;1792-1797.

7. Grinda J, Couetil JP, Chauvaud S, et al. Cardiac valve papillary fibroelastoma: surgical excision for revealed or potential embolization. J Thorac Cardiovasc Surg 1999;117: 106-110.

8. Gowda RM, Khan IA, Nair CK, Mehta NJ, Vasavada BC, Sacchi TJ. Cardiac papillary fibroelastoma: a comprehensive analysis of 725 cases. Am Heart J 2003; 146, 404-410.

9. Shahian DM. Papillary fibroelastomas. Semin Thorac Cardiovasc Surg 2000;12: 101-110.

10. Walpot J, Hanspasteuning W, Koeman J, Volker P. Papillary fibroelastoma of the aortic valve: a rare cause of stroke. Eur J Echocardiogr 2007;8:489-491.

11. Anastacio MM, Moon MR, Damiano RJ, Pasque MK, Maniar HS, Lawton JS. Surgical experience with cardiac papillary fibroelastoma over a 15-year period. Ann Thorac Surg 2012;94:537-541.

12. Shing M, Rubenson DS. Embolic stroke and cardiac papillary fibroelastoma. Clin Cardiol 2001;24:346-347.

13. Hsu VM, Atluri P, Keane MG, Woo YJ. Minimally invasive aortic valve papillary fibroelastoma resection. Interactive Cardiovasc Thorac Surg 2006;5:779-781. 


\section{Neurology}

\section{Clinical Reasoning: An unusual cause of adult cryptogenic ischemic stroke}

Mark L. Leekoff, Julia E. Masur, Allen P. Burke, et al.

Neurology 2018;90;386-391

DOI 10.1212/WNL.0000000000004995

This information is current as of February 19, 2018

\section{Updated Information \&} Services

\section{References}

Subspecialty Collections

Permissions \& Licensing

Reprints including high resolution figures, can be found at: http://n.neurology.org/content/90/8/386.full

This article cites 13 articles, 2 of which you can access for free at: http://n.neurology.org/content/90/8/386.full\#ref-list-1

This article, along with others on similar topics, appears in the following collection(s):

All Cerebrovascular disease/Stroke

http://n.neurology.org/cgi/collection/all_cerebrovascular_disease_strok

e

Cardiac

http://n.neurology.org/cgi/collection/cardiac

Clinical neurology history

http://n.neurology.org/cgi/collection/clinical_neurology_history

Infarction

http://n.neurology.org/cgi/collection/infarction

MRI

http://n.neurology.org/cgi/collection/mri

Information about reproducing this article in parts (figures,tables) or in its entirety can be found online at:

http://www.neurology.org/about/about_the_journal\#permissions

Information about ordering reprints can be found online:

http://n.neurology.org/subscribers/advertise

Neurology ${ }^{\circledR}$ is the official journal of the American Academy of Neurology. Published continuously since 1951, it is now a weekly with 48 issues per year. Copyright () 2018 American Academy of Neurology. All rights reserved. Print ISSN: 0028-3878. Online ISSN: 1526-632X.

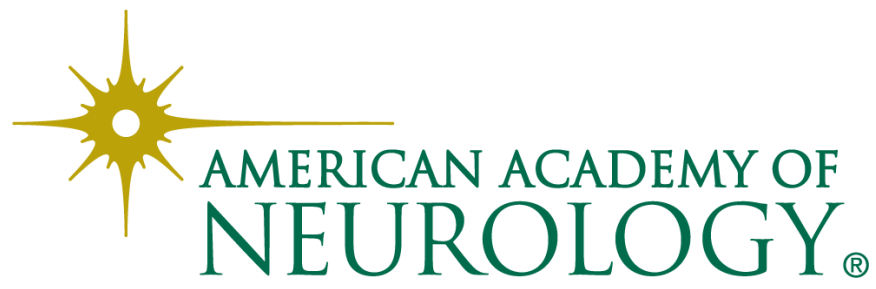

